\title{
Neuronal Birthdate-Specific Gene Transfer with Adenoviral Vectors
}

\author{
Mitsuhiro Hashimoto ${ }^{1}$ and Katsuhiko Mikoshiba ${ }^{1,2}$ \\ ${ }^{1}$ Laboratory for Developmental Neurobiology, RIKEN Brain Science Institute, 2-1 Hirosawa, Wako-shi, Saitama 351-0198, Japan, and ${ }^{2}$ Department of \\ Molecular Neurobiology, The Institute of Medical Science, The University of Tokyo, Tokyo 108-8639, Japan
}

The multilayered structure of the cerebral cortex has been studied in detail. Early-born neurons migrate into the inner layer and late-born neurons migrate into more superficial layers, thus establishing an inside-out gradient. The progenitor cells appear to acquire layerspecific properties at the time of neuronal birth; however, the molecular mechanisms of cell-fate acquisition are still unclear, because it has been difficult to identify a cohort of birthdate-related progenitor cells. Using replication-defective adenoviral vectors, we successfully performed "pulse gene transfer" into progenitor cells in a neuronal birthdate-specific manner. When adenoviral vectors were injected into the midbrain ventricle of mouse embryos between embryonic day 10.5 (E10.5) and E14.5, the adenoviral vectors introduced a foreign gene into a specific cohort of birthdate-related progenitor cells. The virally infected cohorts developed normally into cortical neurons and formed the canonical cortical layers in an inside-out manner. This technique allows us to distinguish a cohort of birthdate-related progenitor cells from other progenitor cells with different birthdates and to introduce a foreign gene into specific subsets of cortical layers by performing adenoviral injection at specific times. This adenovirus-meditated gene transfer technique will enable us to examine the properties of each subset of progenitor cells that share the same neuronal birthdate.

Key words: neuronal birthdate; gene transfer; cerebral cortex; adenoviral vector; development; laminar structure

\section{Introduction}

Early in embryonic development, multipotent progenitor cells in the ventricular zone (VZ) progressively give rise to cortical neurons after multiple cell divisions (Luskin et al., 1988; Price and Thurlow, 1988; Walsh and Cepko, 1988; Reid et al., 1995). An early progenitor cell generates two distinct daughter cells after a mitotic division. This event is referred to as the neuronal birthdate of the daughter cell that is committed to a neuronal fate. The committed neuron leaves the cell cycle and migrates out to the cortical plate (CP) to occupy its mature position in the developing cerebral cortex (CC) (Angevine and Sidman, 1961).

Neuronal birthdate analyses with tritiated thymidine (Angevine and Sidman, 1961; Rakic, 1974) or bromodeoxyuridine (BrdU) (Miller and Nowakowski, 1988) have indicated that the earliest-born neurons come to lie in the deepest cortical layer and that the latest-born ones migrate into the most superficial layer. Thus, the laminar structure of the CC is established in an insideout developmental gradient. Each layer consists of neurons that share similar birthdates as well as common morphologies, functional properties, and projection patterns (for review, see McConnell, 1988). Transplantation studies have clearly revealed that

Received May 21, 2003; revised Nov. 6, 2003; accepted Nov. 6, 2003

This study was supported by Special Coordination Funds of the Ministry of Education, Culture, Sports, Science, and Technology of the Japanese Government. We thank Drs. A. Nagy and M. Tanaka for providing the Z/AP transgenic mouse, Y. Hisano for technical assistance, and Drs. T. Miyata and M. Ogawa for helpful discussions and comments pertaining to this manuscript.

Correspondence should be addressed to Dr. Mitsuhiro Hashimoto at the above address. E-mail: mhashimoto@brain.riken.go.jp.

DOI:10.1523/JNEUROSCI.2529-03.2004

Copyright $\odot 2004$ Society for Neuroscience $\quad$ 0270-6474/04/240286-11\$15.00/0 the progenitor cells express properties characteristic of their cortical layer-specific cell fate just before their neuronal birthdate (McConnell, 1988; McConnell and Kaznowski, 1991; Frantz and McConnell, 1996). Therefore, establishment of cell fate in progenitor cells closely correlates with their neuronal birthdates.

Progenitor cells show altered patterns of gene expression over time (Frantz et al., 1994; Burrows et al., 1997). This suggests that the progenitor cells are intrinsically different at each neuronal birthdate. Their intrinsic changes appear to regulate their commitment to specific laminar phenotypes, but the molecular mechanisms mediating the sequential generation of diverse laminar phenotypes from a multipotent progenitor cell population are not yet clear. If we could identify properties of particular subsets of progenitor cells that share the same neuronal birthdate, we could begin to understand more clearly the molecular mechanisms of cortical neurogenesis, but such a task has proven difficult.

To address this problem, we used replication-defective adenoviral vectors to introduce foreign genes into developing progenitor cells in the VZ. Adenoviral vectors expressing a marker gene were injected into a midbrain ventricle of mouse embryos. Remarkably, the marker was introduced by the adenoviral vectors on the day of adenoviral infection into a subset of progenitor cells that share the same neuronal birthdate. These birthdate-specific labeled progenitor cells differentiated normally into cortical neurons and formed specific cortical layers in an inside-out manner. By using adenoviral vectors, we can thus introduce a foreign gene into developing progenitor cells in a neuronal birthdate-specific manner. This adenovirus-mediated gene transfer technique will illuminate molecular properties of birthdate-related progenitor 
cell populations and mechanisms by which cortical laminar structures are formed.

\section{Materials and Methods}

Preparation of recombinant adenoviral vectors. The adenoviral vectors AdexCAG-NL-LacZ, AdexCAG-HSVtk, and AdexCAG-NL-Cre are diagramed in Figure $1 A$. AdexCAG-NL-LacZ expresses nuclear-targeted $\beta$-galactosidase ( $\beta$-gal) (NL-LacZ) under the control of a strong, ubiquitous CAG promoter, as described previously (Hashimoto et al., 1996). AdexCAG-HSVtk expresses herpes simplex virus thymidine kinase (HSVtk) as a suicide gene under the control of the CAG promoter. AdexCAG-NL-Cre expresses nuclear-targeted Cre recombinase (NLCre) under the control of the CAG promoter (Kanegae et al., 1995). AdexCAG-HSVtk was constructed as follows: A $2.8 \mathrm{kbp} \mathrm{BglII-BamHI}$ fragment from pTKS (Wigler et al., 1978) coding HSVtk and polyadenylation signal was inserted into the SwaI cloning site of pAdexlpCAw (Hashimoto et al., 1996), and then the pAdexCAG-HSVtk cosmid vector was constructed. The adenoviral vector AdexCAG-HSVtk was derived from pAdexCAG-HSVtk using a modification of the COS-TPC method (Miyake et al., 1996). The adenoviral vector (Adex series) is based on human adenovirus type 5 (Ad5), and is replication incompetent because it lacks the E1A, E1B, and E3 regions of its genome. Each clone was checked by restriction enzymatic digestion (restriction analysis) and PCR for E1A (Zhao et al., 1998) to not include parent adenoviruses. Adenoviral vectors were purified and concentrated by double cesium step-gradient centrifugation (Hashimoto et al., 1996). The titers of viral stocks were determined by plaque assay on human embryonic kidney 293 cells.

Injection of adenoviral vectors. Pregnant Institute of Cancer Research (ICR) mice (Slc:ICR; NipponSLC, Hamamatsu, Japan) and pregnant Z/AP transgenic mice (Lobe et al., 1999) (refer to Fig. 7A) were housed in a controlled environment [RIKEN Brain Science Institute (BSI) animal facility] under a regulated $12 \mathrm{hr}$ light/dark cycle. All procedures involving animal preparation were approved by the RIKEN BSI Animal Committee. The day when a vaginal plug was detected was counted as embryonic day 0.5 (E0.5).

Manipulation of mouse embryos was performed according to a modification of exo utero surgery (Muneoka et al., 1986; Turner and Cepko, 1987). This manipulation is illustrated in Figure $1 B$. Adenoviral vectors (total, $1 \times 10^{8} \mathrm{pfu}$ ) were injected into the midbrain ventricle of the embryos on E10.5, E11.5, E12.5, E13.5, and E14.5. AdexCAG-NL-LacZ was used to label the adenovirus-infected cells. For the cell lineage analysis of the adenovirus-infected cells, AdexCAG-NL-Cre was injected into the E11.5 embryos of Z/AP mice. For cell ablation experiments, AdexCAG-HSVtk was injected into mouse embryos at E11.5 and, subsequently, the pregnant mice were injected intraperitoneally with $30 \mathrm{mg} / \mathrm{kg}$ body weight ganciclovir (GCV; Sigma-Aldrich, Tokyo, Japan) at E12.5. After the adenoviral injection, the embryos were carefully placed into the abdominal cavity and the body wall muscle and skin were closed with sutures. At E18.5, surviving embryos were delivered by cesarean section. The newly delivered mice were fostered to dams. The next day, E19.5, was designated as postnatal day $0(\mathrm{P} 0)$. In each case, four pregnant mice, each with 6-10 embryos on the manipulated side of the uterine horn, were injected with the adenoviral vectors and analyzed. The manipulated animals were maintained in a clean environment.

BrdU labeling. A mixture of AdexCAG-NL-LacZ (total, $2.5 \times 10^{7} \mathrm{pfu}$ ) and BrdU (total, $2.5 \mu \mathrm{g}$; Sigma-Aldrich) was injected into the midbrain ventricle of mouse embryos on E11.5. When the injections of AdexCAG$\mathrm{NL}-\mathrm{LacZ}$ and BrdU were sequentially performed, BrdU was injected into the abdominal cavity of the manipulated pregnant dams ( $50 \mu \mathrm{g} / \mathrm{gm}$ body weight). At E18.5, the embryos were fixed and sectioned transversely as described below.

Histochemical analysis. The manipulated mice were fixed by transcardiac perfusion with $4 \%$ paraformaldehyde in $0.1 \mathrm{M}$ phosphate buffer, $\mathrm{pH}$ 7.4, at E18.5, P20, and P23. Subsequently, the brains were removed, further fixed in the same fixative for $1 \mathrm{hr}$ at $4^{\circ} \mathrm{C}$, and rinsed in $\operatorname{PBS}(-)$. To detect $\beta$-gal activity, fixed whole brains were stained with Bluo-gal (Invitrogen, Tokyo, Japan) solution (Hashimoto et al., 1996) for several hours at room temperature. Human placental alkaline phosphate (hAP) activity in the Z/AP mice was detected by a staining method as described previously (Lobe et al., 1999). The brains were cryoprotected by serial equilibration in sucrose $[10,15$, and $20 \%(\mathrm{w} / \mathrm{v})$ in PBS $(-)]$ at $4^{\circ} \mathrm{C}$. In some cases, the brains were sliced transversely, with the aid of brain matrices (15003; Ted Pella, Redding, CA). They were sectioned transversely on a cryostat (CM3000; Jung, Nussloch, Germany). The cryostat sections were rinsed in PBS(-) and either used for immunohistochemistry or counterstained with neutral red (Sigma-Aldrich) or cresyl violet (Merck, Tokyo, Japan).

Immunohistochemistry. Cryostat sections were treated as described previously (Hashimoto et al., 1996) with goat polyclonal anti-adenoviral hexon (1:50; Chemicon, Hofheim, Germany), goat polyclonal anticalretinin (1:500; Chemicon), or rabbit polyclonal anti-phospho-histone $\mathrm{H} 3$ (pHistone) as a mitotic cell marker (1:100; Upstate Biotechnology, Lake Placid, NY). Anti-hexon immunoreactivity was detected by FITCconjugated anti-goat IgG (1:200; Jackson ImmunoResearch, West Grove, PA). Anti-calretinin or anti-pHistone immunoreactivity was detected using an $\mathrm{ABC}$ kit (Vector Laboratories, Burlingame, $\mathrm{CA}$ ) and 3,3' diaminobenzidine tetrahydrochloride (DojnDo, Kumamoto, Japan). Some sections were double-immunostained with mouse monoclonal anti-adenoviral hexon (1:50; HyTest, Turku, Finland) and rabbit polyclonal anti-pHistone (1:100). These immunoreactivities were detected by rhodamine-conjugated goat anti-mouse IgG (1:200; ICN/Cappel, Costa Mesa, CA) and FITC-conjugated goat anti-rabbit IgG (1:200; ICN/Cappel). Some sections were counterstained with cresyl violet (Merck).

The cryostat sections of the BrdU-labeled brains were incubated with $2 \mathrm{~N} \mathrm{HCl}$ and $0.5 \%(\mathrm{w} / \mathrm{v})$ Triton $\mathrm{X}-100$ for $30 \mathrm{~min}$ and subsequently neutralized with $\mathrm{PBS}(-)$. They were immunostained with monoclonal anti-BrdU antibody (1:100; BD Biosciences, San Jose, CA). Anti-BrdU immunoreactivity was detected with rhodamine-conjugated goat antimouse IgG (1:200; ICN/Cappel). After washing with PBS(-), the sections were incubated with rabbit polyclonal anti- $\beta$-gal antibody (1:50; ICN/Cappel). Anti- $\beta$-gal immunoreactivity was detected with FITCconjugated anti-rabbit IgG (1:200; ICN/Cappel). These antibodies were diluted with PBS $(-)$ containing $1 \%(\mathrm{w} / \mathrm{v})$ BSA and $0.1 \%(\mathrm{w} / \mathrm{v})$ Tween 20. Optical images were obtained with an Olympus BX50 microscope (Olympus Optical, Tokyo, Japan).

\section{Results}

Throughout this report, we use abbreviations in the form "E11.5: P20." The left side (E11.5) indicates the embryonic stage at which the adenoviral vector was injected, and the right side (P20) is the age at which the mice were analyzed.

\section{Adenoviral infection on the ventricular surface}

Adenoviruses are bound to cell surfaces by a coxsackie B and adenovirus type 2 and 5 receptor (CAR) (Bergelson et al., 1997; Tomko et al., 1997). The mouse CAR is already expressed in embryonic brain at E10.5 (Honda et al., 2000). Adenoviruses anchored to a cell surface penetrate into host cells by receptormediated endocytosis and quickly release their genomic DNA into the nuclei of the host cells within $1 \mathrm{hr}$ (Greber et al., 1993). During this process, an adenoviral capsid, hexon, is also transferred into the cells (Greber et al., 1993). Thus, cells infected with adenoviruses can be detected with anti-hexon antibody.

AdexCAG-NL-LacZ (Fig. $1 A$ ) was injected into the midbrain ventricles of embryos on E10.5 (Fig. $1 B$ ). Five hours after injection, the embryos were sectioned transversely and stained with polyclonal anti-hexon antibody (Fig. 1C). Anti-hexon immunoreactivity was observed on all ventricular surfaces. This indicates that after the injection, the adenoviral vectors quickly spread throughout all ventricles and penetrated into the neuroepithelial cells.

AdexCAG-NL-LacZ was injected into the midbrain ventricle of E11.5 embryos. Two hours after the injection, the embryo was fixed and sectioned transversely on a cryostat. The sections were 
A

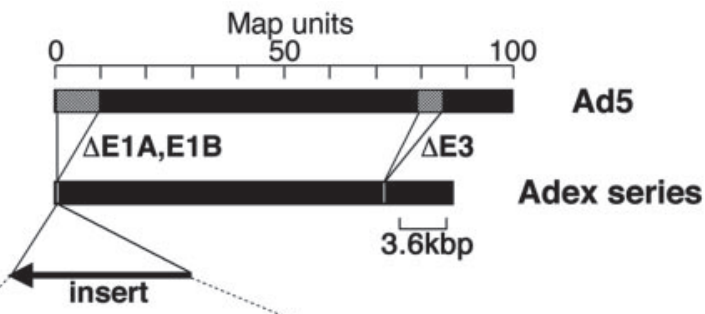

$<$ Name $>$

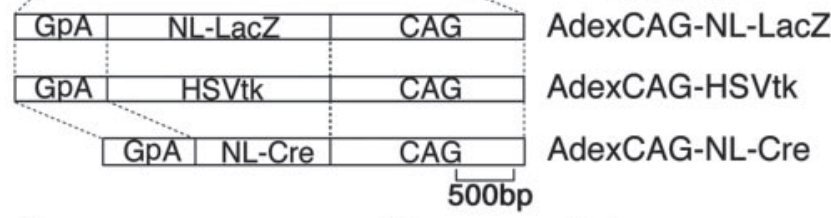

B

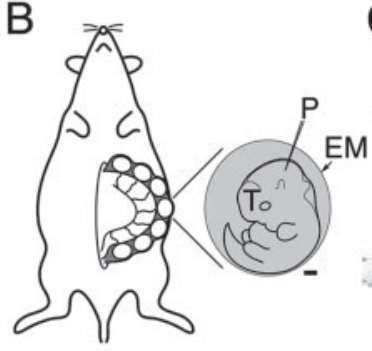

C<smiles>[Te]=[Ge]C1CC1</smiles><smiles>C1C[Te][Te]1</smiles>

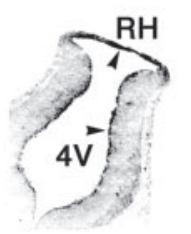

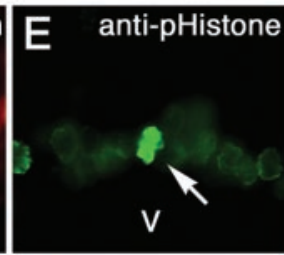
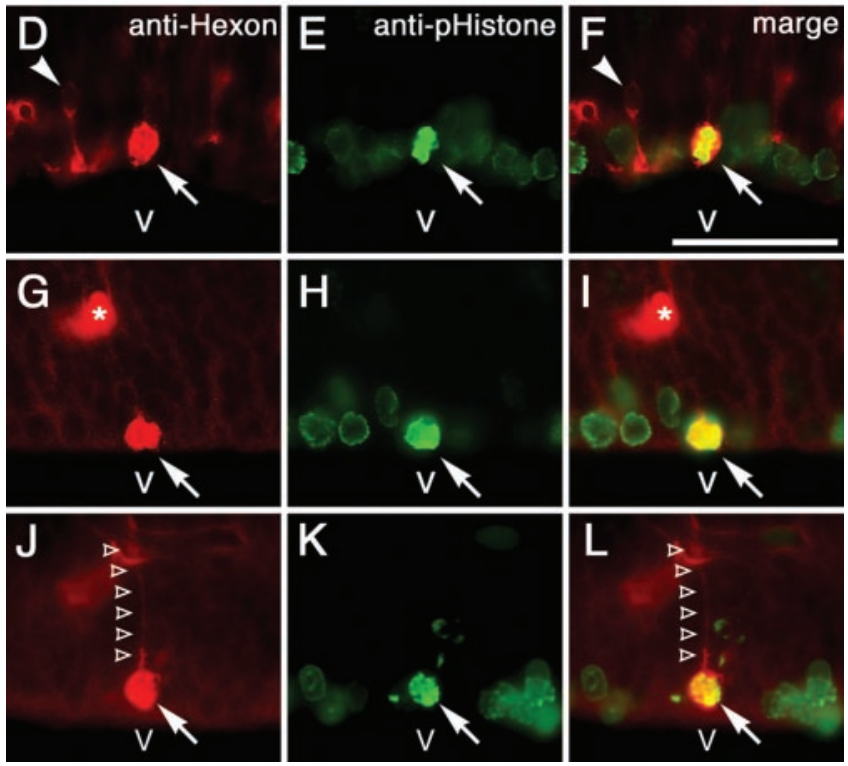
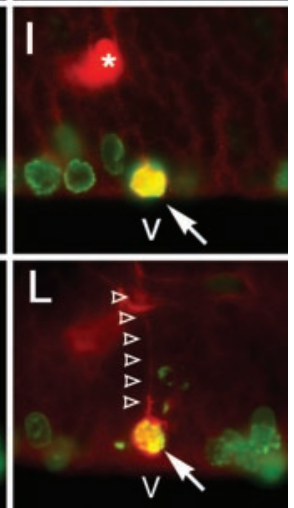

Figure 1. Construction of adenoviral vectors and adenoviral injection. $A$, Replicationincompetent adenoviral vectors (Adex series) that lack the E1A, E1B, and E3 region were generated from human Ad5. An expression unit was inserted into the E1A-E1B deleted region. AdexCAG-NL-LacZ expresses NL-LacZ. AdexCAG-HSVtk expresses HSVtk as a suicide gene. AdexCAG-NL-Cre expresses NL-Cre. B, Embryos were manipulated by exo utero surgery (see Materials and Methods). Exposed embryos (E10.5) lapped with external embryonic membrane (EM: yolk sac and amnion) are illustrated. Scale bar, $500 \mu \mathrm{m}$. Adenoviral vectors were injected into the midbrain ventricle with a heat-pulled glass pipette $(P)$. C, Five hours after injection of AdexCAG-NL-LacZ into E10.5 embryo, brains were sectioned transversely and stained with polyclonal anti-hexon antibody. Anti-hexon immunoreactivity was observed along the ventricular surfaces (arrowheads). Scale bar, $500 \mu \mathrm{m} . D-L$, Two hours after injection of AdexCAG-NL-LacZ into E11.5 embryos, brains were sectioned transversely and double-immunostained with monoclonal anti-hexon (indicated in red; $D$, $G, J$ ) and, as a mitotic-cell marker, polyclonal anti-pHistone (indicated in green; $E, H, K$ ). $F, I$, and $L$ indicate the merged view of $D$ and $E, G$ and $H$, and $J$ and $K$, respectively. Scale bar, $50 \mu \mathrm{m}$. Arrows indicate the cell bodies of hexon- and pHistone-positive cells. The hexonand pHistone-positive cells in $D-F$ and $G-L$ may be undergoing metaphase and anaphase, respectively. The hexon-and pHistone-positive cell in $J-L$ has a short ascending process
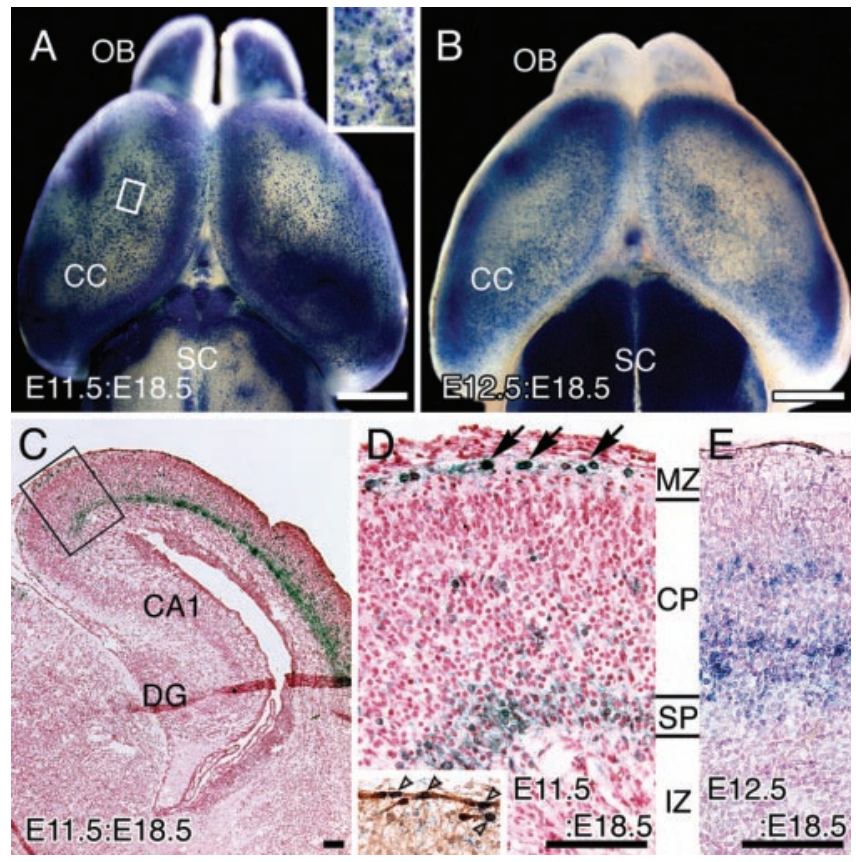

Figure 2. Distribution of $\beta$-gal-positive cells in E11.5:E18.5 and E12.5:E18.5 brains. AdexCAG-NL-LacZ was injected into the midbrain ventricles of embryos at E11.5 and E12.5. At E18.5, each manipulated brain was stained for $\beta$-gal by whole mount. Dorsal views of the E11.5:E18.5 $(A)$ and E12.5:E18.5 $(B)$ brains are indicated. A high-magnification view of the area indicated by the white box in $A$ is shown as an inset at the top right of $A$. Transverse cryosections from E11.5:E18.5 $(C, D)$ and E12.5:E18.5 $(E)$ brains were counterstained with neutral red. A high-magnification view of the box in ( is shown in $D$. The $\beta$-gal-positive cells in E11.5:E18.5 brains are located in the marginal zone (MZ; arrows in $D$ ) and subplate (SP). The inset in $D$ indicates a neighboring section of $D$ stained with anti-calretinin antibody. Unfilled arrowheads indicate $\beta$-gal- and calretinin-positive cells in the marginal zone of a E11.5:E18.5 brain. $\beta$-galpositive cells in E12.5:E18.5 brains ( $E$ ) are located in the CP. CA1, Hippocampal CA1 region; DG, dentate gyrus; IZ, intermediate zone; $\mathrm{OB}$, olfactory bulb; $S C$, superior coliculus. Scale bars: $A, B$, $1 \mathrm{~mm} ; C-E, 100 \mu \mathrm{m}$.

double-immunostained with monoclonal anti-hexon and polyclonal anti-pHistone antibodies (Fig. $1 D-L$ ). We used the antipHistone antibody as a mitotic cell marker. Anti-hexon immunoreactivity was mainly observed in progenitor cells located on the ventricular surface (Fig. $1 D, G, J$, arrows); these cells were also positive for the mitotic cell maker pHistone (Fig. 1E,H,K, arrows). Some of these cells have a short ascending process (Fig. $1 J, L$, unfilled arrowheads). This indicates that the adenoviral vectors infect progenitor cells undergoing mitosis on the ventricular surface sometime within the first $2 \mathrm{hr}$ after adenoviral infection.

\section{Distribution of infected neurons in embryonic}

\section{cerebral cortex}

After the injection of AdexCAG-NL-LacZ, E11.5:E18.5 (Fig. 2A) and E12.5:E18.5 (Fig. $2 B$ ) brains were fixed and stained for $\beta$-gal by whole mount. These brains showed strong $\beta$-gal activity in the CC, olfactory bulb and superior colliculus, but the pattern of $\beta$-gal staining was somewhat different in the two populations. Many $\beta$-gal-positive cells were observed on the surface of the CC

\section{$\leftarrow$}

(unfilled arrowheads). Arrowheads in $D$ and $F$ indicate a hexon-positive cell in $G_{1}$ phase that appears to be migrating away from the ventricular surface. Asterisks indicate blood vessels. 4V, Fourth ventricle; $\mathrm{CAG}$, ubiquitous and strong promoter; $\mathrm{GPA}$, poly-A region of rabbit $\beta$-globin; $\mathrm{T}$, telencephalon; $\mathrm{FB}$, forebrain ventricle; $\mathrm{HB}$, hindbrain ventricle; $\mathrm{LT}$, lamina terminalis; $\mathrm{RH}$, roof of hindbrain; $V$, ventricle. 
in the E11.5:E18.5 brain (Fig. 2A, inset), but there are no such cells in the E12.5:E18.5 brain (Fig. $2 B$ ). To examine more closely the distribution of $\beta$-gal-positive cells in the E11.5:E18.5 and E12.5:E18.5 brains, we transversely sectioned them and counterstained them with neutral red (Fig. $2 C-E$ ). In the E11.5:E18.5 brain (Fig. 2C,D), $\beta$-gal-positive cells are localized in the marginal zone (future layer I) and in the subplate (future layer VI). In contrast, $\beta$-gal-positive cells in the E12.5:E18.5 brain exist only in the CP (Fig. $2 E$ ). The distribution of $\beta$-gal-positive cells within the CC was entirely different from the E11.5:E18.5 brain and the E12.5:E18.5 brain. Almost all of the $\beta$-gal-positive cells were determined to be neurons, based on their morphological and immunohistochemical properties.

The $\beta$-gal-positive cells in the marginal zone of the E11.5: E18.5 brain (Fig. 2D, arrows) may be Cajal-Retzius (C-R) cells, because these cells were also positive for the C-R cell marker calretinin (Fig. 2D, inset, unfilled arrowheads) (del Rio et al., 1995). This result indicates that the progenitor cells that were infected with the adenoviral vector on E11.5 generated C-R cells and subplate neurons; in contrast, the progenitor cells infected on E12.5 produced CP neurons. This difference in distribution corroborates findings of neuronal birthdate analyses by pulselabeling with tritiated thymidine (Angevine and Sidman, 1961) and BrdU (Miller and Nowakowski, 1988). These analyses indicated that C-R cells and subplate neurons are generated first during cortical neurogenesis, and subsequently CP neurons are generated and migrate radially into the region between the marginal zone and subplate (for review, see Allendoerfer and Shatz, 1994; Marin-Padilla, 1998). Thus, CP neurons are younger than C-R cells and subplate neurons.

\section{Relationship between adenoviral gene transfer and BrdU labeling}

An exogenous DNA precursor, BrdU, is used to study cell proliferation in the developing nervous system and has been useful in the study of neuronal birthdates (Miller and Nowakowski, 1988). It is generally accepted that only cells in the S-phase of the cell cycle at the time of a single abdominal injection of BrdU incorporate BrdU into their chromosomal DNA (pulse-labeling), and the day of BrdU injection corresponds to the birthdate of neurons that are strongly labeled with BrdU.

To determine the birthdate of a cortical neuron infected with AdexCAG-NL-LacZ, we directly injected BrdU together with AdexCAG-NL-LacZ into the midbrain ventricle of E11.5 embryos. BrdU was not incorporated into the adenoviral genomic DNA, because the adenoviral vector used was replication incompetent. Seven days after the adenoviral injection, the E11.5:E18.5 brains were sectioned transversely and double-immunostained with anti- $\beta$-gal (Fig. $3 A, D$ ) and anti-BrdU (Fig. 3B,E) antibodies. Anti- $\beta$-gal immunoreactivity (Fig. $3 A, D$ ) was localized to the marginal zone and subplate, as in the $\beta$-gal-staining experiment (Fig. 2C,D). Anti-BrdU immunoreactivity was also localized to the marginal zone and subplate (Fig. $3 B, E$ ). In these regions, three types of cells ( $\beta$-gal-positive, BrdU-positive, and $\beta$-gal- and BrdU-double-positive) were observed, with a large fraction of the $\beta$-gal-positive cells also positive for BrdU (Fig. $3 C, F$ ). Anti- $\beta$-gal and anti-BrdU immunoreactivity was found in the nuclei of the double-positive cells (Fig. 3D-F, insets). This indicates that the double-positive cells were born on the day of injection.

Next, we injected the mixture of AdexCAG-NL-LacZ and BrdU into the midbrain ventricle of E12.5 embryos (Fig. 4). These embryos were fixed on E18.5 and sectioned transversely on a cryostat. The sections were double-immunostained with anti-

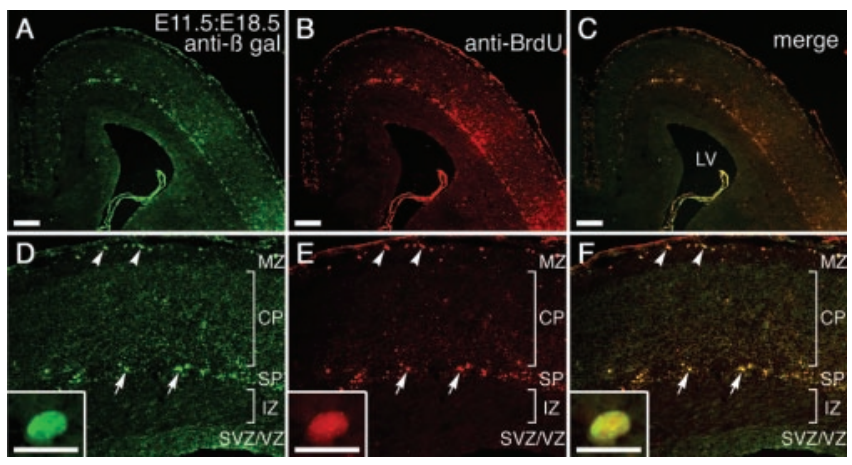

Figure 3. BrdU labeling of an E11.5:E18.5 brain. A mixture of AdexCAG-NL-LacZ and BrdU was injected into the midbrain ventricle of an embryo on E11.5. At E18.5, the E11.5:E18.5 brain was sectioned transversely and double-immunostained with anti- $\beta$-gal (shown in green; $A, D$ ) and anti-BrdU (shown in red; $B, E$ ) antibodies. Arrowheads and arrows indicate double-positive C-R cells and subplate (SP) neurons, respectively. A high-magnification view of the doublepositive subplate neuron is shown in insets in $D-F$. The CP and intermediate zone (IZ) are almost entirely $\beta$-gal- and BrdU-negative. LV, Lateral ventricle; MZ, marginal zone. Scale bars: 200 $\mu \mathrm{m}$; insets, $20 \mu \mathrm{m}$.

BrdU and anti- $\beta$-gal antibodies (Fig. $4 A-C, G^{\prime}$ ). Anti- $\beta$-gal (Fig. $4 A$ ) and anti-BrdU (Fig. $4 B$ ) immunoreactivity was seen together in the bottom layer of the $\mathrm{CP}$ (Fig. $4 \mathrm{C}$ ), as in the $\beta$-gal-staining experiment (Fig. $2 E$ ). This region includes the following types of cells: $\beta$-gal-single-positive (indicated in green), BrdU-singlepositive (indicated in red), and $\beta$-gal- and BrdU-double-positive (Fig. 4C, arrowheads, yellow). This mixed cell population was consistently observed.

This mixed cell population reflects an important difference between adenoviral infection and BrdU labeling. Adenoviral vectors infect progenitor cells undergoing $\mathrm{M}$-phase on the ventricular surface (Fig. 1D-L). In contrast, BrdU labels progenitor cells in S-phase in the outer half of the VZ (Takahashi et al., 1993). Consequently, right after the simultaneous injection of AdexCAG-NL-LacZ and BrdU (Fig. 4G, 0 hr cell cycle), the adenoviral vectors (M-phase; green-filled circles) and BrdU (Sphase; red-filled circles) label different fractions of the proliferating cell population in the VZ. For the first hour (Fig. 4G, 0 and 1 hr cell cycles), the mitotic cells on the ventricular surface are only labeled by the adenoviral vectors and thus appear as $\beta$-gal-singlepositive (green-filled circles) cells with labeling, because it takes $\sim 2 \mathrm{hr}$ for the BrdU-labeled cells (red-filled circles) to descend from the outer half of the VZ to the ventricular surface and enter into M-phase (Takahashi et al., 1993). Two hours after the simultaneous injection (Fig. 4G, $2 \mathrm{hr}$ cell cycle), the BrdU-labeled cells enter into $\mathrm{M}$-phase and are infected with the adenoviral vectors; thus, they appear as double-positive for $\beta$-gal and BrdU with labeling (yellow-filled circles). These temporal differences between the labeling events underlie the establishment of the mixed cell population. This result also suggests that the adenoviral vectors continue to infect the mitotic cells on the ventricular surface for $>2 \mathrm{hr}$ (Fig. 4G, 2-4 hr cell cycles).

How long do the adenoviral vectors remain capable of infecting the mitotic cells on the ventricular surface? To examine this question, we performed sequential injections of the adenoviral vector and BrdU at different embryonic stages (Fig. $4 D-F, H^{\prime}$ ). First, AdexCAG-NL-LacZ was injected into the midbrain ventricle of E12.5 embryos. Fifteen hours after the adenoviral injection, we injected BrdU into the abdominal cavity of the manipulated pregnant dams (Fig. $4 D-F$ ). At E18.5, the embryos were fixed and transversely sectioned on a cryostat. The sections were 

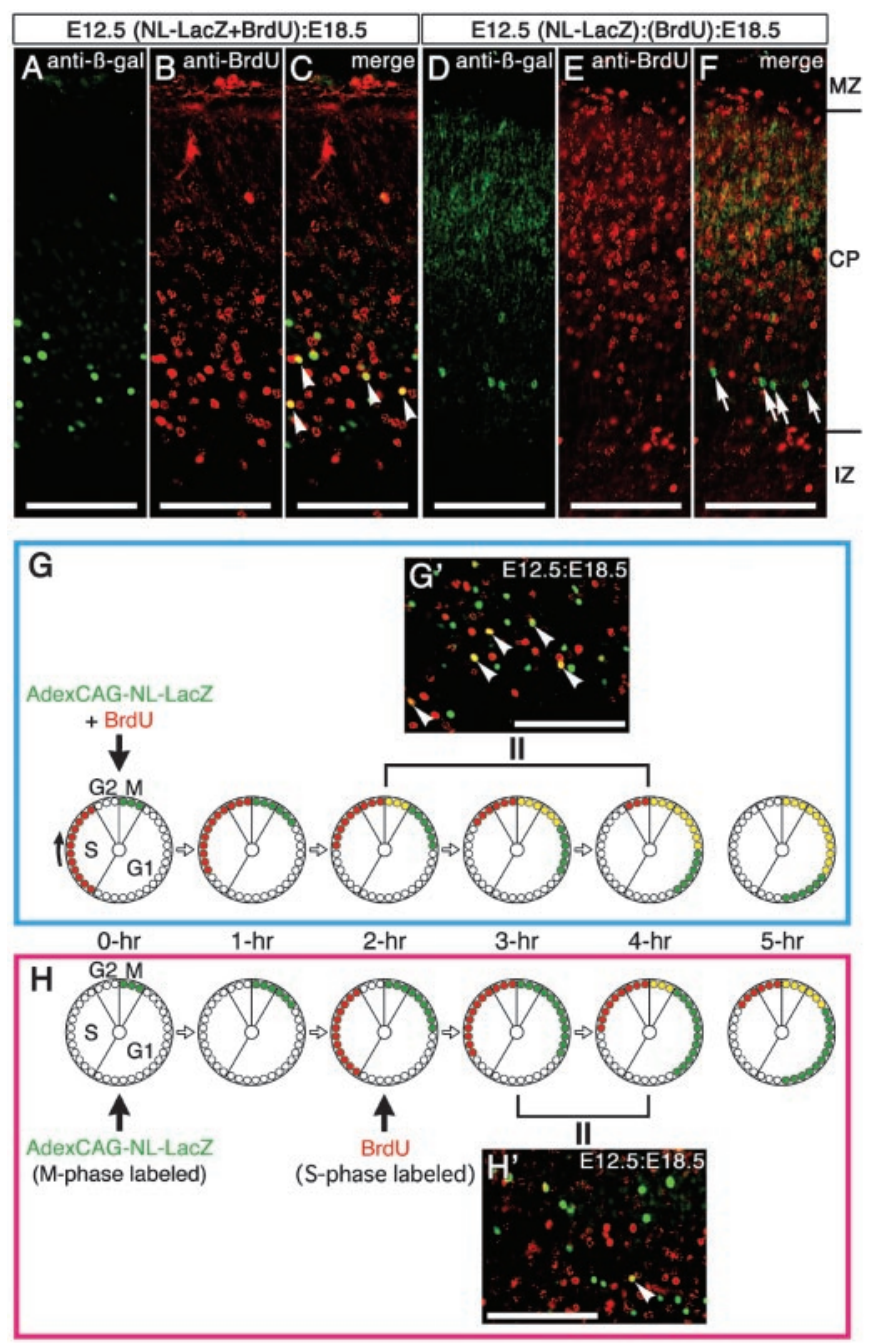

Figure 4. Feature of adenovirus-mediated gene transfer into embryonic brain. AdexCAGNL-LacZ and BrdU were simultaneously injected into the midbrain ventricle of E12.5 mouse embryos $\left(A-C, G^{\prime}\right)$. In the other cases, AdexCAG-NL-LacZ and BrdU were injected at separate times $\left(D-F, H^{\prime}\right)$ : first, AdexCAG-NL-LacZ was injected into the midbrain ventricle of E12.5 embryos, and then $15(D-F)$ or $2\left(H^{\prime}\right)$ hr after the adenoviral injection, BrdU was injected into the abdominal cavity of the manipulated pregnant dams. At E18.5, the embryos were fixed and sectioned transversely on a cryostat. The transverse sections were double-immunostained with anti- $\beta$-gal and anti-BrdU antibodies. After the simultaneous injection, the following celllabeling patterns were seen in the cortical plate of the E12.5:E18.5 brain $\left(C, G^{\prime}\right)$ : $\beta$-gal-positive cells (shown in green), BrdU-positive cells (shown in red), and $\beta$-gal-and BrdU-double-positive cells (shown in yellow). In contrast, after injection at separate times, the population of doublepositive cells (shown in yellow) in the E12.5:E18.5 brains $\left(F, H^{\prime}\right)$ was not observed $(F)$ or was greatly reduced $\left(H^{\prime}\right)$. The diagram in $G$ indicates the labeling schedule for the experiment using simultaneous injection of BrdU and adenoviral vectors. Arrowheads in $C, G^{\prime}$, and $H^{\prime}$ indicate $\beta$-gal- and BrdU-double positive cells (shown in yellow). Arrows in $F$ indicate $\beta$-gal-singlepositive cells. The diagram in $H$ indicates the labeling schedule for the experiment in which BrdU and adenoviral vector were applied at different times. One cell cycle is illustrated by a large circle, as shown at the lower left in $G$. The cell cycle progresses in a single direction (from $G_{1}$ to $S$, $G_{2}$, and $M$ phases). The small red-filled circles indicate the fractions of proliferating cells that are labeled with BrdU during S-phase. The small green-filled circles indicate the fractions of proliferating cells that are infected with AdexCAG-NL-LacZ during M-phase and were found with labeling to be positive for $\beta$-gal. The small yellow-filled circles indicate the BrdU- and $\beta$-galdouble-positive cells. One small circle is equivalent to $\sim 20 \mathrm{~min}$ on one cell cycle. IZ, Intermediate zone; MZ, marginal zone. Scale bar, $100 \mu \mathrm{m}$.

double-immunostained with anti- $\beta$-gal (Fig. $4 D$ ) and anti-BrdU (Fig. $4 E$ ) antibodies. No double-positive cells were observed (Fig. $4 F$, arrows). At the time of the BrdU injection, the cell cycle that was occurring at the time of the adenoviral injection had finished, and the following cell cycle was already in progress (Takahashi et al., 1995). Thus, the injected BrdU labeled the population of proliferating cells that were undergoing this next cell cycle, suggesting that the effective time of the uptake of adenoviral vectors was $<15 \mathrm{hr}$ and, thus, less than the period of a single cell cycle. Next, we shortened the interval between adenoviral and BrdU injections. AdexCAG-NL-LacZ was injected into E12.5 embryos (Fig. $4 \mathrm{H}, 0 \mathrm{hr}$ cell cycle). Two hours after the adenoviral injection, we injected BrdU into the abdominal cavity of the manipulated pregnant dams (Fig. 4H, $2 \mathrm{hr}$ cell cycle). At E18.5, the embryos were fixed and sectioned on a cryostat. The sections were doubleimmunostained with anti-BrdU and anti- $\beta$-gal antibodies (Fig. $4 H^{\prime}$ ). Four hours after the adenoviral injection (Fig. $4 H, 4 \mathrm{hr}$ cell cycle), the BrdU-labeled cells entered into M-phase (yellow-filled circles), because $2 \mathrm{hr}$ had passed since the BrdU injection. If the adenoviral vectors continued infecting the mitotic cells on the ventricular surface for $>4 \mathrm{hr}$, double-positive cells should be observed (Fig. $4 \mathrm{H}, 4$ and $5 \mathrm{hr}$ cell cycles, yellow-filled circles). However, it was difficult to find any double-positive cells in the E12.5-E18.5 cortical plate (Fig. $4 H^{\prime}$ ), which indicates that the adenoviral vectors cease infecting mitotic cells on the ventricular surface within $4 \mathrm{hr}$ of the adenoviral injection (Fig. $4 \mathrm{H}, 3 \mathrm{or} 4 \mathrm{hr}$ cell cycles).

Distribution of the infected neurons in adult cerebral cortex AdexCAG-NL-LacZ was injected into the midbrain ventricles of embryos on E12.5, E13.5, and E14.5. At P20, E12.5:P20, E13.5: P20, and E14.5:P20 brains were stained for $\beta$-gal by whole mount. All showed overall high $\beta$-gal activity, but the specific staining patterns were different between them. To reveal the distribution of $\beta$-gal-positive cells in each adult brain, we sectioned them transversely (Fig. 5). $\beta$-gal-positive cells were plainly localized in layers V, IV, and II-III of the E12.5:P20, E13.5:P20, and E14.5:P20 neocortices, respectively (Fig. 5, left, middle, and right columns, respectively). Almost all of the $\beta$-gal-positive cells were neurons. These results indicate that early-infected progenitor cells (e.g., E12.5) came to lie in the inner layer (e.g., layer V), whereas late-infected progenitor cells (e.g., E14.5) migrated to the outer layer (e.g., layer II-III), and, thus, the virally infected progenitor cells revealed an inside-out developmental gradient. These results correspond to neuronal birthdate analyses with tritiated thymidine (Angevine and Sidman, 1961; Smart and Smart, 1982) and BrdU (Miller and Nowakowski, 1988).

The $\beta$-gal-positive cell populations were distributed in different areas of the CNS. Many $\beta$-gal-positive neurons were observed in the posterolateral cortical amygdaloid nucleus (APL), posteromedial cortical amygdaloid nucleus (APM), hypothalamus, and olfactory tubercle of E12.5:P20 (Fig. 5A,G) and E13.5:P20 (Fig. $5 B, H)$ brains, but the caudate putamen (CAU), hippocampus, and thalamic regions of E12.5:P20 and E13.5:P20 brains were negative for $\beta$-gal. In contrast, $\beta$-gal-positive cells were found only rarely in the APL, APM, CAU, olfactory tubercle, and thalamic regions of E14.5:P20 brains, but the pyramidal neurons in the CA1 and CA2 regions of the hippocampus were strongly positive for $\beta$-gal (Fig. 5I,L). The results indicate that the pyramidal neurons in the CA1 and CA2 regions of the hippocampus are generated after E14.5 (Figs. 5I,L, 6C). In contrast, neurons in thalamic regions were generated before E11.5 (Fig. 6A,B).

In the E12.5:P20 brain (Fig. $5 A, G$ ), $\beta$-gal-positive cells were more abundant in the lateral limbic cortex (LC) and paleocortex (PC) than in the dorsal neocortex. In the E13.5:P20 brain (Fig. $5 H$ ), there were clearly fewer $\beta$-gal-positive neurons in the posterolateral neocortex (Fig. $5 H$, between arrow and arrowhead), 

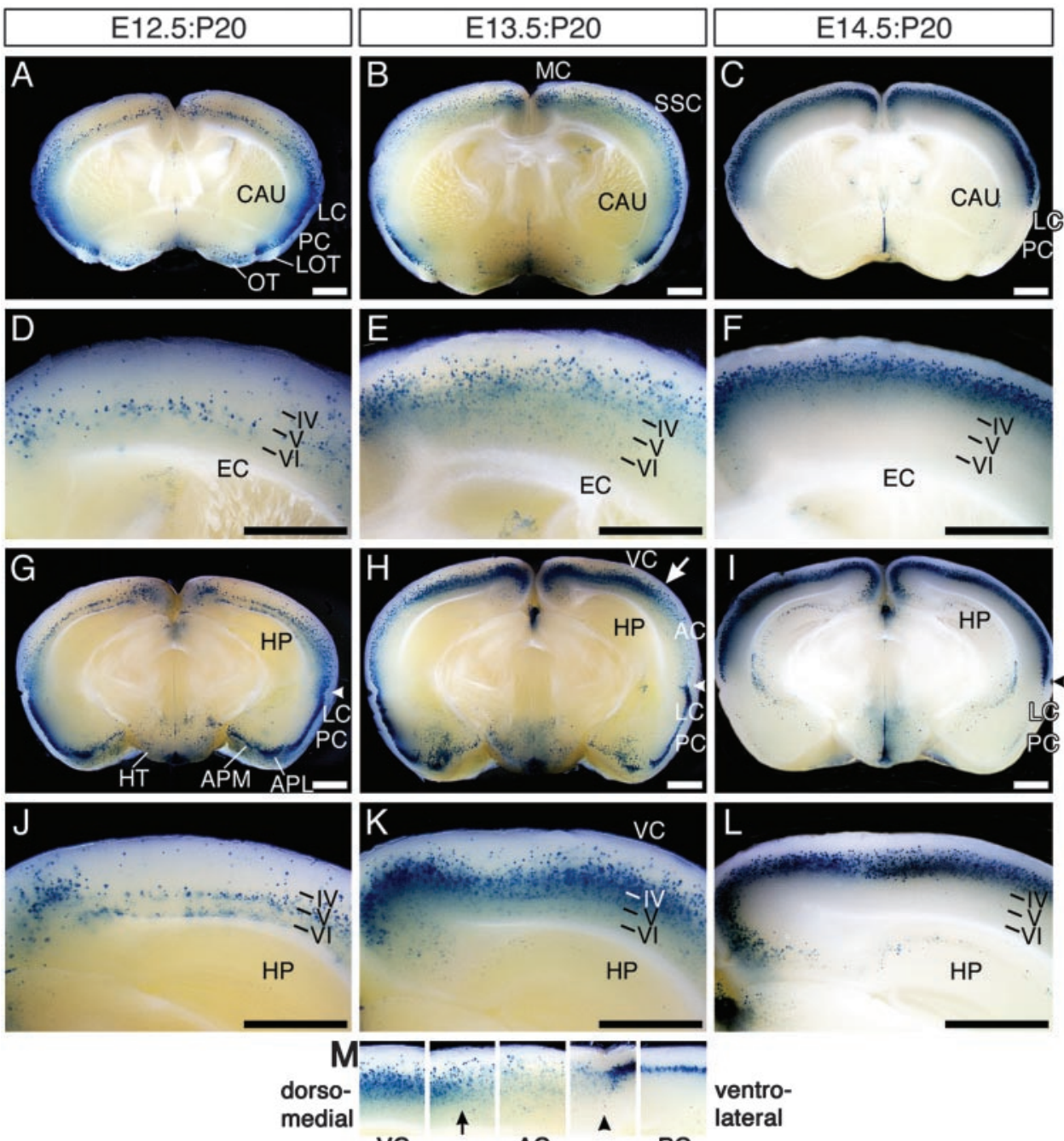

ventro-

VC

AC

PC

Figure 5. Transverse sections of E12.5:P20, E13.5:P20, and E14.5:P20 brains. E12.5:P20 (left column), E13.5:P20 (middle column), and E14.5:P20 (right column) brains were sectioned transversely. $A-F$ and $G-L$ indicate the anterior and posterior regions of each brain, respectively. Arrowheads in $G-I$ and $M$ indicate the rhinal fissure. The boundary between the dorsal part of the auditory cortex and the lateral part of the secondary visual cortex in the E13.5:P20 brain is indicated by the white arrow in $H$ and the arrow in $M$. Each cortical region in $H$ is arranged in line in M. IV-VI, The layer number in the cerebral cortex; AC, primary auditory cortex; EC, external capsule; HP, hippocampus; $\mathrm{HT}$, hypothalamus; LOT, lateral olfactory tract; $\mathrm{MC}$, primary motor cortex; $0 \mathrm{~T}$, olfactory tubercle; SSC, primary somatosensory cortex; VC, primary visual cortex. Scale bar, $1 \mathrm{~mm}$.

which includes the primary auditory cortex, than in the LC-PC. The boundary between these regions was plainly observed just under the rhinal fissure (Fig. 5H,M, arrowhead, supplemental Fig. S1 $B$, broken line, available at www.jneurosci.org). In contrast, in E14.5:P20 brains, almost all of the $\beta$-gal-positive cells were located in the neocortex (Fig. 5C,I), and the extent of $\beta$-galpositive cells ceased under the rhinal fissure (Fig. 5I, arrowhead, supplemental Fig. S1 D, broken line, available at www.jneurosci. org). These results suggest that neurogenesis of the LC and PC may precede that of the neocortex and may be complete by E14.5.

In the E13.5:P20 brain (Fig. $5 H$ ), the posterodorsal neocortex, which includes the primary visual cortex (Fig. $5 \mathrm{H}, \mathrm{VC}$ ), contained more $\beta$-gal-positive neurons than the posterolateral neocortex (Fig. $5 H$, between the arrow and the arrowhead), primary motor cortex (Fig. 5B, MC), and primary somatosensory cortex (Fig. 5B, SSC). This difference in cell population clearly delineated the boundary between the posterodorsal neocortex and other regions (Fig. 5H,M, arrow, supplemental Fig. S1 A, B, arrows, available at www.jneurosci.org). This result suggests that the number of cortical neurons that are generated from the VZ on
E13.5 determines in part the boundaries between several cortical regions.

In contrast to the specific $\beta$-gal expression domains observed in response to adenoviral gene transfer, when the E18.5 and P20 brains of the Z/AP transgenic mouse that ubiquitously expresses $L a c Z$ gene under the control of the CAG promoter (Fig. 7A) were fixed and stained for $\beta$-gal, the entire brain and all CC layers were positive for $\beta$-gal (data not shown). This indicates that the transcriptional activity of the CAG promoter is not regulated by intrinsic factors in a cortical layer-specific manner. In addition, the activity and specificity of gene expression from adenoviral vectors reflects the activity and specificity of promoter elements on adenoviral vectors (Hashimoto et al., 1996). Thus, the observed specific distribution of $\beta$-gal-positive cells cannot be ascribed to selective transcriptional activity of the CAG promoter on the adenoviral vector.

\section{Influence of adenoviral infection on cortical neurogenesis}

In general, replication-deficient retroviral vectors are used to introduce a foreign gene into progenitor cells in the $\mathrm{VZ}$ at various 

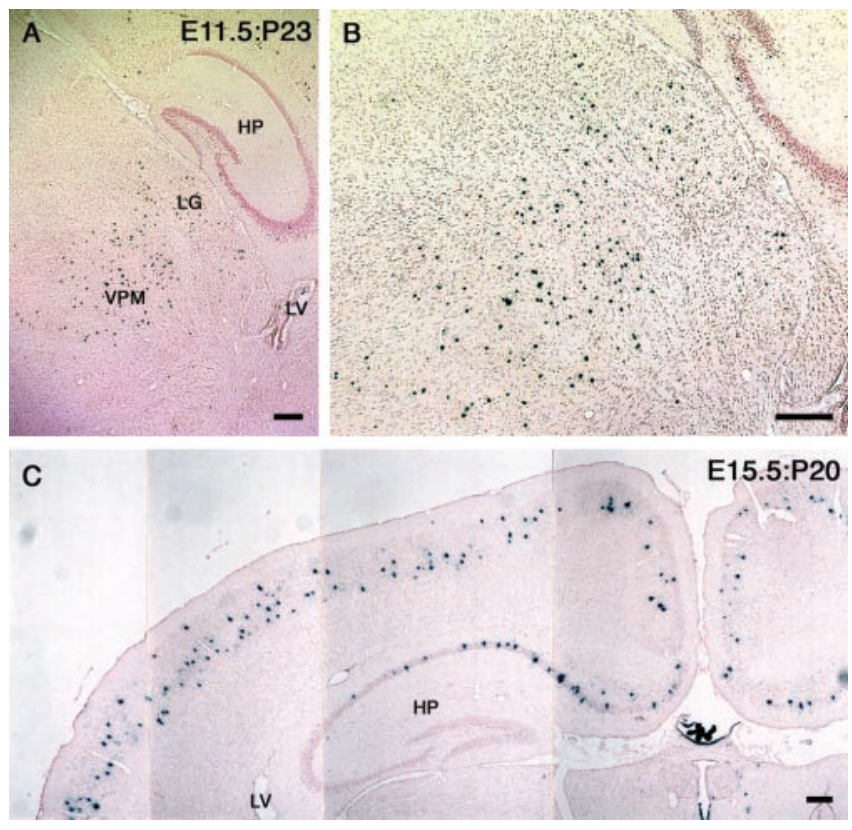

Figure 6. Localization of $\beta$-gal-positive cells in E11.5:P23 and E15.5:P20 brains. AdexCAG$\mathrm{NL}-\mathrm{LacZ}$ was injected into the midbrain ventricles of embryos on E11.5 and E15.5. These E11.5: P23 and E15.5:P20 brains were fixed and sectioned transversely on a cryostat. The sections were stained for $\beta$-gal and with neutral red. Many $\beta$-gal-positive cells were observed in the thalamic region of E11.5:P23 brains $(A)$. B shows a high-magnification view of $A$. The cerebral cortex and hippocampus of an E15.5:P20 brain are indicated in $C$. The pyramidal neurons in the CA1 and CA2 regions of the E15.5:P20 hippocampus were positive for $\beta$-gal. HP, Hippocampus; $L G$, lateral geniculate nucleus; LV, lateral ventricle; VPM, ventroposteromedial nucleus of the thalamus. Scale bar, $200 \mu \mathrm{m}$.

embryonic stages. Retrovirus-mediated gene transfer is useful for lineage tracing of progenitor cells, because the retroviral genome is integrated into the chromosomal DNA and passed on to all of the progeny. Retroviral lineage-tracing experiments have indicated that early progenitor cells in the VZ are normally multipotent, and that they gave rise to progeny spanning many cortical layers after multiple cell divisions (Luskin et al., 1988; Price and Thurlow, 1988; Walsh and Cepko, 1988; Reid et al., 1995). However, our results indicate that virally infected progenitor cells generate a subset of cortical neurons that have given laminar identities according to the day of adenoviral injection. It appears that there are subsets of progenitor cells that are specifically destined to generate specific cortical layers; adenoviral vectors label each specific subset at the time of adenoviral injection. To examine the ability of progenitor cells infected with adenoviral vectors to preserve their multipotency to produce many laminar layers, and indeed whether there exist such subsets of fate-marked progenitor cells, we injected AdexCAG-NL-Cre (Fig. 1A) into the midbrain ventricle of E11.5 embryos of Z/AP transgenic mice (Lobe et al., 1999), a reporter mouse for Cre-mediated recombination (Fig. 7A). The progenitor cells infected with AdexCAGNL-Cre switched their gene expression from $L a c Z$ gene to hAP by Cre excision (Fig. 7A). Because the $h A P$ gene was coded in the chromosomal DNA, the progeny of infected progenitor cells were marked by hAP. After the injection, E11.5:E18.5 (Z/AP) brains were fixed, sectioned transversely, and stained for hAP. Many hAP-positive cells (shown in purple) were observed on the sections (Fig. $7 B-D$ ), and they spanned many cortical layers. This indicates that progenitor cells infected with adenoviral vectors could progressively generate progeny spanning many cortical layers, and suggests that infection with an adenoviral vector does

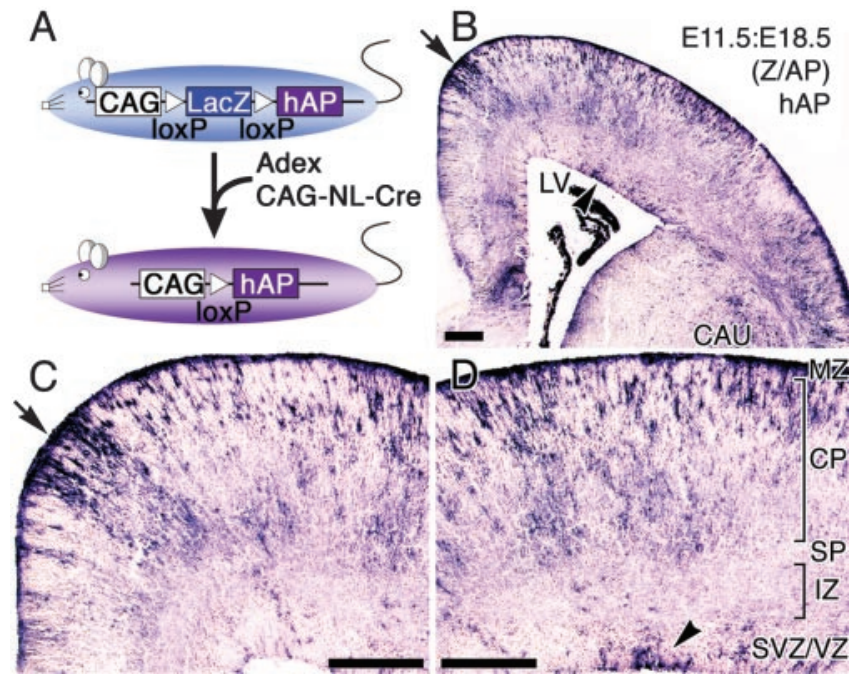

Figure 7. Clonally related cells are labeled by adenovirus-mediated gene induction on a Z/AP mouse. The system of adenovirus-mediated gene induction in the Z/AP mouse is illustrated in A.Z/AP mice ubiquitously express the LacZ gene under the control of the CAG promoter. When Cre recombinase is introduced into the Z/AP mouse by AdexCAG-NL-Cre (Fig. 1A), it removes the $L a c Z$ gene from the chromosomal DNA and a second reporter, the hAP gene, is expressed instead $(A)$. AdexCAG-NL-Cre was injected into the midbrain ventricle of the Z/AP embryo at E11.5. E11.5:E18.5 Z/AP brains were sectioned transversely and stained for hAP (shown in purple). Transverse sections are shown in $B-D$. Arrowheads and arrows in $B-D$ indicate hAP-positive cells in the VZ and thickly labeled-cells in the marginal zone (MZ) and CP, respectively. LV, Lateral ventricle; IZ, intermediate zone; SP, subplate. Scale bar, $200 \mu \mathrm{m}$.

not affect the multipotency of developing progenitor cells. Moreover, if a subset of fate-marked progenitor cells exists in the developing brain, the distribution of hAP-positive cells in the E11.5: E18.5 (Z/AP) brain (Fig. 7B,D) should be identical to the distribution of $\beta$-gal-positive cells in the E11.5:E18.5 brain (Fig. $3 A, D)$. However, our results show that these two distributions differ significantly. This suggests that no population of progenitor cells exists on the ventricular surface of that E11.5 brain that is predetermined to produce a given laminar layer. This observation is supported by a previous study (Cai et al., 2002).

\section{Destruction of specific neurons}

AdexCAG-HSVtk expresses the HSVtk gene under the control of the CAG promoter (Fig. 1A). Proliferating cells infected with AdexCAG-HSVtk can be killed selectively by GCV administration (data not shown), because the HSVtk converts the nontoxic GCV to phosphorylated GCV that terminates DNA synthesis (Field et al., 1983). However, nondividing cells, including neurons, infected with AdexCAG-HSVtk would not be killed by GCV.

AdexCAG-HSVtk was injected into the midbrain ventricle of embryos on E11.5. Subsequently, GCV was injected once into the dams at E12.5. Approximately $60 \%$ of the manipulated embryos survived until E18.5. The embryos could draw breath after cesarean section, but they appeared to be unable to grow because of a severely abnormal appearance characterized primarily by an extremely narrow head (Fig. $8 \mathrm{~A}$ ). In contrast, littermates that were not injected with AdexCAG-HSVtk but were treated with GCV showed a normal phenotype (Fig. $8 \mathrm{~B}$ ). The brains of manipulated embryos (Fig. $8 C, E$ ) were also smaller than the brains of littermates (Fig. 8D,F). The size of the CC and cerebellum was clearly reduced. Clots of blood were observed characteristically within the ventricles of manipulated embryos (Fig. $8 E$, arrowheads). E11.5:E18.5 manipulated and control brains were sectioned 

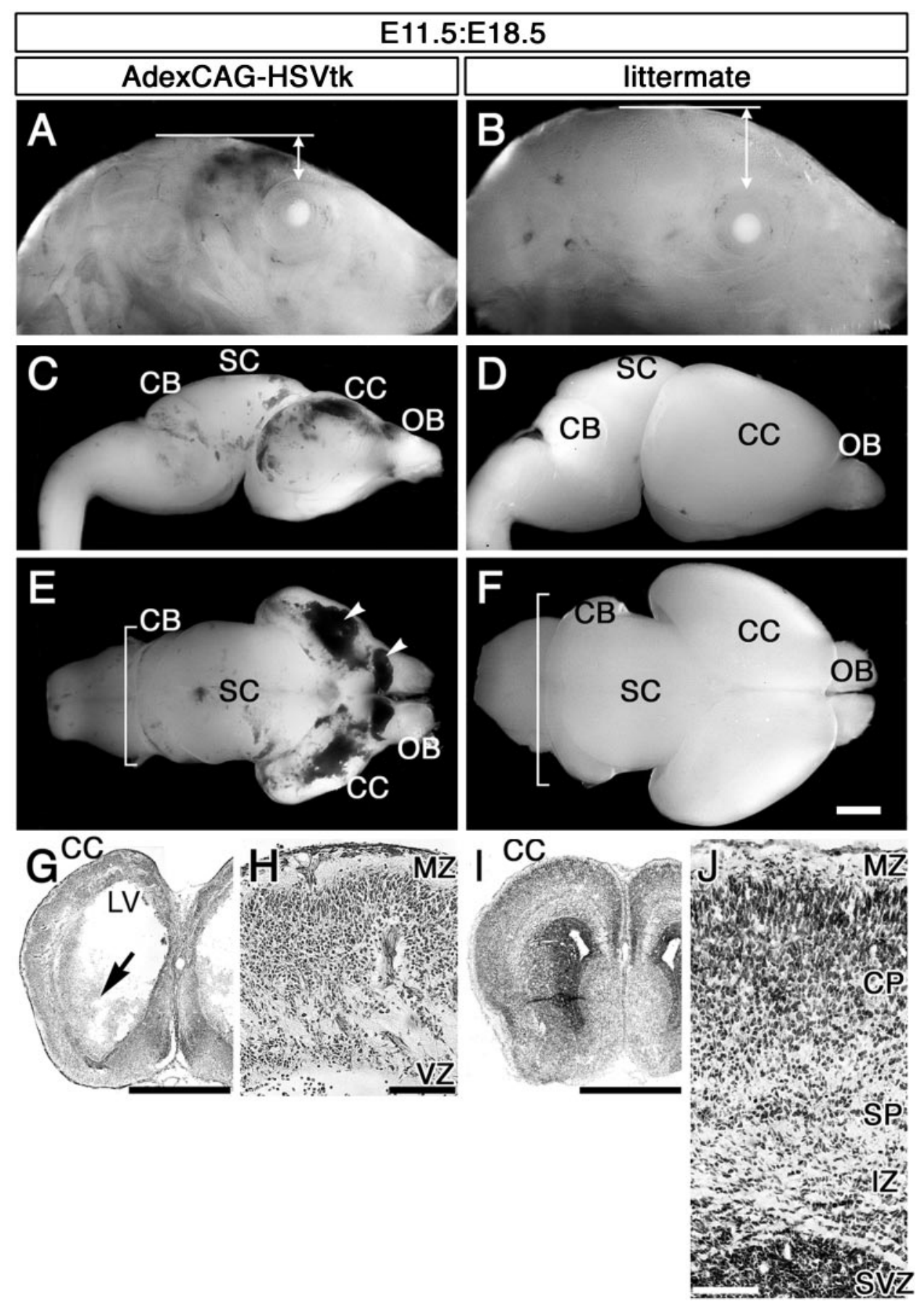

Figure 8. Ablation of C-R cells and subplate neurons with AdexCAG-HSVtk and GCV. The left column shows the head ( $A$, lateral view) and brain (C, lateral view; $E$, dorsal view) of E11.5:E18.5 mice injected with AdexCAG-HSVtk at E11.5 and treated with GCV. The right column shows the head ( $B$, lateral view) and brain ( $D$, lateral view; $F$, dorsal view) of a littermate that was not injected with AdexCAG-HSVtk but was treated with GCV as a control. Arrowheads in $E$ indicate blood clots. Square brackets in $E$ and $F$ indicate the longitudinal size of the cerebellum (CB). A transverse section of the E11.5:E18.5 manipulated brain, which was stained with cresyl violet, is indicated in $G$ and $H$. The arrow in $G$ shows the destroyed SVZ of the striatum and CAU. LV, Lateral ventricle; MZ, marginal zone; $0 B$, olfactory bulb; SC, superior coliculus; SP, subplate. Scale bars: (in $F) A-G, 1 \mathrm{~mm} ; H, 100 \mu \mathrm{m}$.

transversely on a cryostat and stained with cresyl violet (Fig. $8 G-$ $J$ ). In sections of manipulated brain (Fig. $8 G, H$ ), the cerebral morphology was severely disordered. The thickness of and cell number within the CC were reduced, and the laminar formation was indistinct compared with the control brain (Fig. 8I,J). In addition, the subventricular zone (SVZ) of the striatum and the CAU was destroyed in manipulated brains (Fig. 8G, arrow). When E12.5 embryos were manipulated with AdexCAG-HSVtk and GCV in the same way, the E12.5:E18.5 manipulated embryos showed a phenotype different from that of the E11.5:E18.5 manipulated embryo (data not shown). The shape of the E12.5:E18.5 cerebral cortex is nearly equal to a normal E18.5 control brain (Fig. $8 B, D, F$ ). In addition, they could also grow to at least $\mathrm{P} 10$ (data not shown).

\section{Discussion}

This study reported an adenovirus-mediated gene transfer into the mouse embryo. When adenoviral vectors are injected into the 


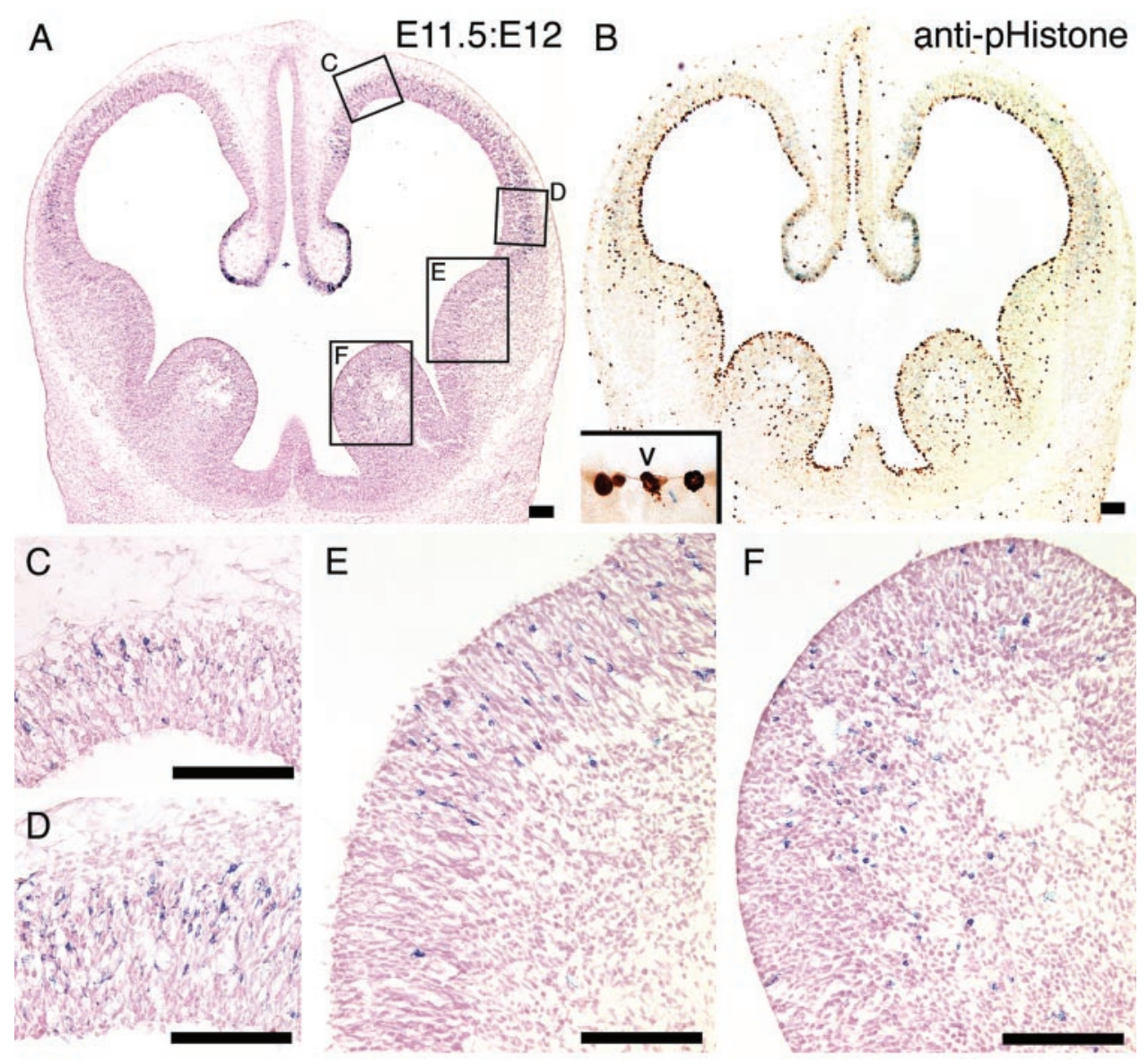

Figure 9. Distribution of $\beta$-gal-positive cells in E11.5:E12 brain. AdexCAG-NL-LacZ was injected into the midbrain ventricle of the E11.5 embryos. Twelve hours (E12) after the adenoviral injection, the embryos were fixed and sectioned transversely. The sections were stained for $\beta$-gal and with neutral red $(A)$. C and $D$ are high-magnification views of the dorsomedial and ventrolateral regions of the cerebral cortex sections shown in $A$. Eand $F$ are high-magnification views of the medial and lateral ganglionic eminences from $A$. The neighboring sections were stained for $\beta$-gal and, as a mitotic cell marker, with anti-pHistone antibody $(B)$. The nuclei and cell bodies of progenitor cells undergoing mitosis are located on the ventricular surface, and their cell bodies are swollen and exposed to the ventricle ( $B$, inset). V, Ventricle. Scale bar, $100 \mu \mathrm{m}$.

midbrain ventricle of the mouse embryo using this technique, the adenoviral vectors can infect progenitor cells on the ventricular surface and introduce a foreign gene into them in a neuronal birthdate-specific manner. This adenovirus-mediated gene transfer could illuminate mechanisms by which cortical laminar structures are formed.

\section{Features of adenovirus-mediated gene transfer}

Adenovirus-mediated gene transfer into the mouse embryonic brain has the following seven features: (1) Adenoviral vectors injected into a single ventricle of the embryonic brains spread throughout all ventricles (Fig. $1 C$ ) to infect progenitor cells undergoing mitosis on the ventricular surface (Fig. 1D-L). (2) The adenoviral infection begins within $2 \mathrm{hr}$ after the adenoviral injection (Fig. $1 D-L$ ), and the adenoviral vectors remain able to infect the mitotic cells on the ventricular surface for up to $\sim 4 \mathrm{hr}$ (Fig. $4 G, H)$. The adenoviral vectors in the embryonic ventricle complete their infection of mitotic cells within $4 \mathrm{hr}$ after the adenoviral injection. (3) Adenoviral infection does not terminate the cell cycle of the progenitor cells. Cortical progenitor cells in mice undergo a maximum of 11 cell cycles during neurogenesis (Takahashi et al., 1995), and the laminar identity of cortical neurons is decided by the cell cycle number at which they leave the cell cycle (Takahashi et al., 1996, 1999). If the cell cycle of the progenitor cell were terminated by adenoviral infection, the laminar identity of the virally infected progenitor cells would be determined at the time of the adenoviral injection. However, we observed that progenitor cells retain their multipotency after the adenoviral infection (Fig. 7), indicating that adenoviral infection does not terminate the cell cycle of the progenitor cells. Consequently, the results provided by adenovirus-mediated gene transfer reveal the native behavior of progenitor cells derived from the VZ. (4) Adenoviral vectors can introduce a foreign gene into progenitor cells on the ventricular surface in a neural-birthdatespecific manner (Figs. 2-5). (5) Adenoviral genomic DNA is efficiently translocated to the nuclei of progenitor cells after adenoviral infection, but it rarely integrates into the chromosomal DNA (Harui et al., 1999). (6) The efficiency of gene expression from adenoviral vectors depends on the activity of the promoter region on the vector. Consequently, it takes time to detect the activity of gene products from adenoviral vectors. When AdexCAG-NL-LacZ is used, it takes $12 \mathrm{hr}$ to detect the activity of $\beta$-gal (Fig. 9). In contrast, BrdU and tritiated thymidine are immediately incorporated into the genomic DNA of proliferating cells and can be detected $30 \mathrm{~min}$ after their intra-abdominal injection (Takahashi et al., 1993). (7) Progenitor cells that are committed to a neural cell fate stably express the foreign gene from embryonic stages to adulthood (Figs. 2, 5, 9). After adenoviral infection, precursor cells committed to a neuronal cell fate retain the adenoviral genomic DNA because they rarely divide again. In 
addition, adenoviral genomic DNA is stable in the nucleus, because the terminal proteins that are covalently linked to the $5^{\prime}$ termini of each strand of the adenoviral genome protect it from endogenous exonuclease digestion (Dunsworth-Browne et al., 1980).

\section{Neuronal birthdate-specific gene transfer}

BrdU and adenoviral vectors label cells at different points during the cell cycle (Fig. 4G). BrdU is incorporated into proliferating cells undergoing S-phase at the time of BrdU injection (Fig. 4G, 0 hr cell cycle, red filled circles), whereas adenoviral vectors infect mitotic cells on the ventricular surface (Figs. $1 D-L, 4 G, 0 \mathrm{hr}$ cell cycle, green filled circles). In addition, the adenoviral vectors continue infecting the mitotic cells on the ventricular surface for $\sim 4$ $\mathrm{hr}$ after the adenoviral injection. The BrdU-labeled fraction descends from the outer half of the VZ to the ventricular surface and enters into $\mathrm{M}$-phase for the duration of the adenoviral infection. Consequently, the fraction labeled with BrdU partially overlapped with the fraction infected with adenoviral vectors (Fig. 4G, $2-4 \mathrm{hr}$ cell cycles, yellow filled circles). The existence of this overlapping fraction indicates that adenoviral vectors are able to introduce the foreign gene into progenitor cells in a neuronal birthdate-specific manner.

A subpopulation of early progenitor cells generates two distinct daughter cells after an asymmetric cell division (Chenn and McConnell, 1995; Cai et al., 2002). One daughter cell is committed to a neural cell fate and leaves the cell cycle; the other daughter cell re-enters into the cell cycle to propagate the progenitor cell population. When pulse-labeling with tritiated thymidine and BrdU is performed, neurally fated cells are heavily labeled, whereas proliferating daughter cells are only lightly labeled, because the amount of labeled DNA is halved with each cell division in the progeny. It is generally believed that the amount of adenoviral genomic DNA in an infected cell is also halved with every subsequent cell division, because the viral DNA is not replicated and rarely integrates into the host chromosomal DNA (Harui et al., 1999). Thus, if early progenitor cells were labeled with adenoviral vectors (e.g., AdexCAG-NL-LacZ), the proliferating daughter cells would inherit the adenoviral genomic DNA and continue to express the foreign gene (e.g., $\beta$-gal). Consequently, the population of cells expressing a foreign gene would be composed of the cells with different neural birthdates. The lack of overlap in the populations of adenovirus-infected cortical neurons (Fig. $4 F$, arrows, $\beta$-gal-positive cells) and BrdU-labeled cells (Fig. $4 F$, red cells) that were generated in the subsequent cycle of cell division, however, indicates that foreign gene expression from the viral DNA does not continue in the progeny (Fig. $4 D-F$ ). This suggests that this adenovirus-mediated gene expression occurs in a specific population of neuronal birthdate-related cells, but the mechanisms of this control are unclear.

Time is an important factor in the regulation of cell fate acquisition for progenitor cells during neurogenesis. For instance, neuronal birthdate determines cortical laminar identity (McConnell, 1988; McConnell and Kaznowski, 1991; Frantz and McConnell, 1996), the number and length of cell cycles regulates cortical neurogenesis (Takahashi et al., 1999; for review, see Caviness et al., 2000), and the switchover from neurogenesis to gliogenesis is modulated by time (for review, see Sauvageot and Stiles, 2002). However, the molecular mechanisms of cell fate acquisition regulated by developmental time are still unclear. If the embryonic day of adenoviral injection is changed, it is possible to modify genetically a specific cohort generated from VZ at that time. This enables us to examine individually behavior and prop- erties of birthdate-related progenitor cells. Adenovirus-mediated gene transfer enables the study of the molecular mechanisms of neurogenesis, migration, and laminar formation of each neuronal birthdate-related cohort.

\section{Regional specification}

The results suggest that the neurogenesis of the $\mathrm{LC}$ and PC is completed by E14.5, and that the LC and PC acquire a regional specification limiting the cell migration into them (Fig. 5). In fact, rat LC is defined by expression of limbic system-associated membrane protein until E14.5 (for review, see Levitt et al., 1997). Neuronal birthdate may correlate with regional specification of the LC and PC.

In layer IV of the E13.5:P20 neocortex, the population of $\beta$-gal-positive neurons in the posterolateral region of the $\mathrm{CC}$ was clearly less than in the posterodorsal region of the CC (Fig. $5 H, M$, supplemental Fig. S1, available at www.jneurosci.org). This regional differentia in the neuronal birthdate-related cell population is also demonstrated in primate cerebral cortex by labeling analysis with tritiated thymidine, which indicated that primate striate cortex is more abundant in labeled neurons than the neighboring (extrastriate) cortex (Dehay et al., 1993). The layer IV neurons born on E13.5 may be heterogeneous regarding regional cell population. Neuronal birthdate-related cortical neurons may be divided into subpopulations that generate a particular cortical region.

\section{Adenovirus-mediated genetic modification of rodent brain}

If this technique is used, it may be possible to genetically modify a specific subset of neurons in embryonic (Figs. 2-4) and adult (Fig. 5) brains. The subset of precursor cells born on E11.5 that includes C-R cells and subplate neurons (Figs. 2, 3) was genetically modified by AdexCAG-HSVtk and destroyed by GCV. The manipulated embryos exhibited a shrunken brain and abnormal laminar formation of the CC (Fig. 8). A recent study using a transgenic mouse that expresses the HSVtk gene specifically on $\mathrm{C}-\mathrm{R}$ cells and subplate neurons also indicated that the ablation of $\mathrm{C}-\mathrm{R}$ cells and subplate neurons causes a reduction in brain size and abnormal laminar formation (Xie et al., 2002). Accordingly, the abnormal phenotype of the manipulated brain appears to be caused by the ablation of the subset of C-R cells and subplate neurons. The striatal SVZ and CAU were also destroyed by this manipulation (Fig. 8G, arrow). The cells in the striatal SVZ and CAU are generated from the rapidly proliferating progenitor cells in the VZ of the lateral ganglionic eminence (Bhide, 1996; Sheth and Bhide, 1997). Adenoviral vectors can introduce a foreign gene into the progenitor cells in the lateral and medial ganglionic eminence (Fig. 9E,F). These proliferating cells may be destroyed by AdexCAG-HSVtk and GCV, and, consequently, the striatal SVZ and CAU appeared to be reduced.

In conclusion, these observations indicate that adenoviral vectors can be used for neuronal birthdate-specific gene transfer while maintaining normal neurogenesis. This technique enables the genetic modification of specific subsets of progenitor cells that share the same birthdate. Consequently, we can distinguish a cohort of birthdate-related progenitor cells from other progenitor cells with different birthdates and examine the molecular properties of each subset. In future experiments, we plan to genetically modify birthdate-related progenitor cells using several adenoviral vectors that express a regulator of neuronal development or to collect each subset of birthdate-related progenitor cells. We believe that this technique provides a means of examin- 
ing in some detail the molecular mechanisms of cortical laminar formation.

\section{References}

Allendoerfer KL, Shatz CJ (1994) The subplate, a transient neocortical structure: its role in the development of connections between thalamus and cortex. Annu Rev Neurosci 17:185-218.

Angevine JB, Sidman RL (1961) Autoradiographic study of cell migration during histogenesis of cerebral cortex in the mouse. Nature 192:766-768.

Bergelson JM, Cunningham JA, Droguett G, Kurt-Jones EA, Krithivas A, Hong JS, Horwitz MS, Crowell RL, Finberg RW (1997) Isolation of a common receptor for Coxsackie B viruses and adenoviruses 2 and 5 . Science 275:1320-1323.

Bhide PG (1996) Cell cycle kinetics in the embryonic mouse corpus striatum. J Comp Neurol 374:506-522.

Burrows RC, Wancio D, Levitt P, Lillien L (1997) Response diversity and timing of progenitor cell maturation are regulated by developmental changes in EGFR expression in the cortex. Neuron 19:251-267.

Cai L, Hayes NL, Takahashi T, Caviness Jr VS, Nowakowski RS (2002) Size distribution of retrovirally marked lineages matches prediction from population measurements of cell cycle behavior. J Neurosci 69:731-744.

Caviness Jr VS, Takahashi T, Nowakowski RS (2000) Neuronogenesis and the early events of neocortical histogenesis. Results Probl Cell Differ 30:107-143.

Chenn A, McConnell SK (1995) Cleavage orientation and the asymmetric inheritance of Notch1 immunoreactivity in mammalian neurogenesis. Cell 82:631-641.

Dehay C, Giroud P, Berland M, Smart I, Kennedy H (1993) Modulation of the cell cycle contributes to the parcellation of the primate visual cortex. Nature 366:464-466.

del Rio JA, Martinez A, Fonseca M, Auladell C, Soriano E (1995) Glutamatelike immunoreactivity and fate of Cajal-Retzius cells in the murine cortex as identified with calretinin antibody. Cereb Cortex 5:13-21.

Dunsworth-Browne M, Schell RE, Berk AJ (1980) Adenovirus terminal protein protects single stranded DNA from digestion by a cellular exonuclease. Nucleic Acids Res 8:543-554.

Field AK, Davies ME, DeWitt C, Perry HC, Liou R, Germershausen J, Karkas JD, Ashton WT, Johnston DB, Tolman RL (1983) 9-([2-hydroxy-1-(hydroxymethyl)ethoxy]methyl)guanine: a selective inhibitor of herpes group virus replication. Proc Natl Acad Sci USA 80:4139-4143.

Frantz GD, McConnell SK (1996) Restriction of late cerebral cortical progenitors to an upper-layer fate. Neuron 17:55-61.

Frantz GD, Weimann JM, Levin ME, McConnell SK (1994) Otx1 and Otx2 define layers and regions in developing cerebral cortex and cerebellum. J Neurosci 14:5725-5740.

Greber UF, Willetts M, Webster P, Helenius A (1993) Stepwise dismantling of adenovirus 2 during entry into cells. Cell 75:477-486.

Harui A, Suzuki S, Kochanek S, Mitani K (1999) Frequency and stability of chromosomal integration of adenovirus vectors. J Virol 73:6141-6146.

Hashimoto M, Aruga J, Hosoya Y, Kanegae Y, Saito I, Mikoshiba K (1996) A neural cell-type-specific expression system using recombinant adenovirus vectors. Hum Gene Ther 7:149-158.

Honda T, Saitoh H, Masuko M, Katagiri-Abe T, Tominaga K, Kozakai I, Kobayashi K, Kumanishi T, Watanabe YG, Odani S, Kuwano R (2000) The coxsackievirus-adenovirus receptor protein as a cell adhesion molecule in the developing mouse brain. Brain Res Mol Brain Res 77:19-28.

Kanegae Y, Lee G, Sato Y, Tanaka M, Nakai M, Sakaki T, Sugano S, Saito I (1995) Efficient gene activation in mammalian cells by using recombinant adenovirus expressing site-specific Cre recombinase. Nucleic Acids Res 23:3816-3821.

Levitt P, Barbe MF, Eagleson KL (1997) Patterning and specification of the cerebral cortex. Annu Rev Neurosci 20:1-24.

Lobe CG, Koop KE, Kreppner W, Lomeli H, Gertsenstein M, Nagy A (1999)
Z/AP, a double reporter for cre-mediated recombination. Dev Biol 208:281-292.

Luskin MB, Pearlman AL, Sanes JR (1988) Cell lineage in the cerebral cortex of the mouse studied in vivo and in vitro with a recombinant retrovirus. Neuron 1:635-647.

Marin-Padilla M (1998) Cajal-Retzius cells and the development of the neocortex. Trends Neurosci 21:64-71.

McConnell SK (1988) Fates of visual cortical neurons in the ferret after isochronic and heterochronic transplantation. J Neurosci 8:945-974.

McConnell SK, Kaznowski CE (1991) Cell cycle dependence of laminar determination in developing neocortex. Science 254:282-285.

Miller MW, Nowakowski RS (1988) Use of bromodeoxyuridineimmunohistochemistry to examine the proliferation, migration and time of origin of cells in the central nervous system. Brain Res 457:44-52.

Miyake S, Makimura M, Kanegae Y, Harada S, Sato Y, Takamori K, Tokuda C, Saito I (1996) Efficient generation of recombinant adenoviruses using adenovirus DNA-terminal protein complex and a cosmid bearing the full-length virus genome. Proc Natl Acad Sci USA 93:1320-1324.

Muneoka K, Wanek N, Bryant SV (1986) Mouse embryos develop normally exo utero. J Exp Zool 239:289-293.

Price J, Thurlow L (1988) Cell lineage in the rat cerebral cortex: a study using retroviral-mediated gene transfer. Development 104:473-482.

Rakic P (1974) Neurons in rhesus monkey visual cortex: systematic relation between time of origin and eventual disposition. Science 183:425-427.

Reid CB, Liang I, Walsh C (1995) Systematic widespread clonal organization in cerebral cortex. Neuron 15:299-310.

Sauvageot CM, Stiles CD (2002) Molecular mechanisms controlling cortical gliogenesis. Curr Opin Neurobiol 12:244-249.

Sheth AN, Bhide PG (1997) Concurrent cellular output from two proliferative populations in the early embryonic mouse corpus striatum. J Comp Neurol 383:220-230.

Smart IH, Smart M (1982) Growth patterns in the lateral wall of the mouse telencephalon. I. Autoradiographic studies of the histogenesis of the isocortex and adjacent areas. J Anat 134:273-298.

Takahashi T, Nowakowski RS, Caviness Jr VS (1993) Cell cycle parameters and patterns of nuclear movement in the neocortical proliferative zone of the fetal mouse. J Neurosci 13:820-833.

Takahashi T, Nowakowski RS, Caviness Jr VS (1995) The cell cycle of the pseudostratified ventricular epithelium of the embryonic murine cerebral wall. J Neurosci 15:6046-6057.

Takahashi T, Nowakowski RS, Caviness Jr VS (1996) Interkinetic and migratory behavior of a cohort of neocortical neurons arising in the early embryonic murine cerebral wall. J Neurosci 16:5762-5776.

Takahashi T, Goto T, Miyama S, Nowakowski RS, Caviness Jr VS (1999) Sequence of neuron origin and neocortical laminar fate: relation to cell cycle of origin in the developing murine cerebral wall. J Neurosci 19:10357-10371.

Tomko RP, Xu R, Philipson L (1997) HCAR and MCAR: the human and mouse cellular receptors for subgroup $\mathrm{C}$ adenoviruses and group $\mathrm{B}$ coxsackieviruses. Proc Natl Acad Sci USA 94:3352-3356.

Turner DL, Cepko CL (1987) A common progenitor for neurons and glia persists in rat retina late in development. Nature 328:131-136.

Walsh C, Cepko CL (1988) Clonally related cortical cells show several migration patterns. Science 241:1342-1345.

Wigler M, Pellicer A, Silverstein S, Axel R (1978) Biochemical transfer of single-copy eucaryotic genes using total cellular DNA as donor. Cell 14:725-731.

Xie Y, Skinner E, Landry C, Handley V, Schonmann V, Jacobs E, Fisher R, Campagnoni A (2002) Influence of the embryonic preplate on the organization of the cerebral cortex: a targeted ablation model. J Neurosci 22:8981-8991.

Zhao H, Ivic L, Otaki JM, Hashimoto M, Mikoshiba K, Firestein S (1998) Functional expression of a mammalian odorant receptor. Science 279: 237-242. 